\title{
SOME CONVERGENCE THEOREMS FOR NEW ITERATION SCHEME IN CAT(0) SPACES
}

\author{
IZHAR UDDIN, JAVID ALI, AND VLADIMIR RAKOČEVIĆ
}

Received 13 December, 2018

\begin{abstract}
In this paper, we construct an iteration scheme involving a hybrid pair of nonexpansive mappings. For this scheme, we prove some convergence theorems in CAT $(0)$ spaces. In process, we remove a restricted condition (also called end-point condition) in previous several existing results. Thus, several relevant results cited in the literature generalize and improve.
\end{abstract}

2010 Mathematics Subject Classification: 47H10; 54H25

Keywords: CAT(0) spaces, fixed point, nonexpansive mapping, iterative scheme

\section{INTRODUCTION}

A metric space $(X, d)$ is a CAT( 0$)$ space if it is geodesically connected and every geodesic triangle in $X$ is at least as thin as its comparison triangle in the Euclidean plane. A complete $\operatorname{CAT}(0)$ space is also called Hadamard space. It is well known that any complete, simply connected Riemannian manifold having non-positive sectional curvature is a CAT(0) space. Other examples are the classes of Pre-Hilbert spaces, $\mathbb{R}$-tress and some others. For more details on these spaces, one can consult [3].

Fixed point theory in $\mathrm{CAT}(0)$ spaces was initiated by Kirk [13] wherein he proved that every single-valued nonexpansive mapping defined on a bounded closed convex subset of a complete CAT $(0)$ space has a fixed point. Since then the fixed point theory for single-valued as well as multi-valued mappings is rapidly developing in complete CAT(0) space (e.g., [4-9]). Here it is worth mentioning that the results in complete $\mathrm{CAT}(0)$ space can be applied to any $\mathrm{CAT}(k)$ space with $k \leq 0$ as any $\mathrm{CAT}(k)$ space is a $\operatorname{CAT}\left(k^{\prime}\right)$ space for every $k^{\prime} \geq k$.

In recent years, different iterative schemes have been used to approximate the fixed points of multi-valued nonexpansive mappings in Banach spaces. Among these iterative schemes, iteration schemes due to Sastry and Babu [17], Panyanak [16] and Song and Wang [23] are notable generalizations of Mann and Ishikawa iteration schemes especially in the case of multi-valued mappings. By now, there exists an extensive 
literature on the iterative fixed points for various classes of mappings. For an up to date account of literature on this theme, we refer the readers to Berinde [2].

In 2010, Sokhuma and Kaewkhao [21] introduced an iteration scheme for a pair of single valued and multivalued mapping and same has been utilized to prove some convergence theorems in Banach spaces. This scheme has also been studied by several authors [1, 19, 20,25] with respect to different class of mappings in different spaces. All the authors proved their results under a very strong condition, i.e. end point condition $T w=\{w\}$ for all $w \in F(T)$, where $T$ is a multi-valued mapping. With a motivation to remove this strong condition, Uddin and Imdad [24] introduced a new iteration scheme for a pair of hybrid mappings in Banach space.

In this paper, we study newly defined iteration scheme due to Uddin and Imdad [24] in complete $\mathrm{CAT}(0)$ space and prove some convergence theorems. In process, several relevant results in Sokhuma and Kaewkhao [21], Akkasriworn et al. [1], Uddin et al. [25], Sokhuma [19], Sokhuma [20] and Uddin and Imdad [24] are generalized and improved.

\section{PRELIMINARIES}

With a view to make, our presentation self contained, we collect some basic definitions and needed results which will be used frequently in the text later.

Let $X$ be a Banach space and $K$ be a nonempty subset of $X$. Let $C B(K)$ be the family of nonempty closed bounded subsets of $K$ while $K C(K)$ be the family of nonempty compact convex subsets of $K$. A subset $K$ of $X$ is called proximinal if for each $x \in X$, there exists an element $k \in K$ such that

$$
d(x, k)=d(x, K)=\inf \{\|x-y\|: y \in K\} .
$$

It is well known that every closed convex subset of a uniformly convex Banach space is proximinal. We shall denote by $P B(K)$, the family of nonempty bounded proximinal subsets of $K$. The Hausdorff metric $H$ on $C B(K)$ is defined as

$$
H(A, B)=\max \left\{\sup _{x \in A} d(x, B), \sup _{y \in B} d(y, A)\right\} \text { for } A, B \in C B(K) .
$$

A multi-valued mapping $T: K \rightarrow C B(K)$ is said to be nonexpansive if

$$
H(T x, T y) \leq\|x-y\| \text {, for all } x, y \in K .
$$

We use the notation $F(T)$ for the set of fixed points of the mapping $T$ while $F(t, T)$ denotes the set of common fixed points of $t$ and $T$, i.e. a point $x$ is said to be a common fixed point of $t$ and $T$ if $x=t x \in T x$. 
Now, we recall some basic geometric properties which are instrumental throughout the discussions. Let $\left\{x_{n}\right\}$ be a bounded sequence in a CAT(0) space $X$. For $x \in X$, write:

$$
r\left(x,\left(\left\{x_{n}\right\}\right)\right)=\limsup _{n \rightarrow \infty} d\left(x, x_{n}\right) .
$$

The asymptotic radius $r\left(\left\{x_{n}\right\}\right)$ is given by

$$
r\left(\left\{x_{n}\right\}\right)=\inf \left\{r\left(x, x_{n}\right): x \in X\right\},
$$

and the asymptotic center $A\left(\left\{x_{n}\right\}\right)$ of $\left\{x_{n}\right\}$ is defined as:

$$
A\left(\left\{x_{n}\right\}\right)=\left\{x \in X: r\left(x, x_{n}\right)=r\left(\left\{x_{n}\right\}\right)\right\} .
$$

It is well known that in a CAT(0) space, $A\left(\left\{x_{n}\right\}\right)$ consists of exactly one point (see Proposition 5 of [7]).

In 2008, Kirk and Panyanak [14] gave a concept of convergence in CAT(0) spaces which is an analogue of weak convergence in Banach spaces and restriction of Lim's concept of convergence [15] to CAT(0) space.

Definition 1 ([14]). A sequence $\left\{x_{n}\right\}$ in $X$ is said to $\Delta$-converge to $x \in X$ if $x$ is the unique asymptotic center of $\left\{u_{n}\right\}$ for every subsequence $\left\{u_{n}\right\}$ of $\left\{x_{n}\right\}$. In this case, we write $\Delta-\lim _{n} x_{n}=x$ and read as $x$ is the $\Delta$-limit of $\left\{x_{n}\right\}$.

Notice that for a given $\left\{x_{n}\right\} \subset X$ which $\Delta$-converges to $x$ and for any $y \in X$ with $y \neq x$ (owing to uniqueness of asymptotic center), we have

$$
\limsup _{n \rightarrow \infty} d\left(x_{n}, x\right)<\limsup _{n \rightarrow \infty} d\left(x_{n}, y\right) .
$$

Thus every CAT $(0)$ space satisfies the Opial property.

Now, we state some basic facts about CAT(0) spaces which will be frequently used throughout the text.

Lemma 1 ([14]). Every bounded sequence in a complete CAT(0) space admits a $\Delta$-convergent subsequence.

Lemma 2 ([8]). If $K$ is closed convex subset of a complete CAT(0) space $X$ and if $\left\{x_{n}\right\}$ is a bounded sequence in $K$, then the asymptotic center of $\left\{x_{n}\right\}$ is in $K$.

Kirk and Panyanak [14] also proved analogoue of famous demiclosedness principle for nonexpansive mappings in $\operatorname{CAT}(0)$ spaces.

Lemma 3. Let $K$ be a closed convex subset of $X$ and $T: K \rightarrow X$ a nonexpansive mapping. If $\left\{x_{n}\right\}$ is a sequence in $X$ which $\Delta$-converges to $x$ and $d\left(x_{n}, T x_{n}\right) \rightarrow 0$, then $x \in K$ and $T x=x$.

The following theorem is a consequence of Theorem 3.2 of Dhompongsa et al. [6]. 
Lemma 4 ([6]). Let $K$ be a nonempty closed convex subset of complete CAT(0) space $X$ and $T: K \rightarrow C(K)$ be a multivalued nonexpansive mapping. If $\Delta-\lim _{n} x_{n}=$ $x$ and $\lim _{n \rightarrow \infty} d\left(T x_{n}, x_{n}\right)=0$, then $x$ is a fixed point of $T$.

Lemma 5 ([9]). Let $(X, d)$ be a CAT(0) space. For $x, y \in X$ and $\alpha \in[0,1]$, there exists a unique $z \in[x, y]$ such that

$$
d(x, z)=\alpha d(x, y) \quad \text { and } \quad d(y, z)=(1-\alpha) d(x, y) .
$$

Notice that we use the notation $(1-\alpha) x \oplus \alpha y$ for the unique point $z$ in the case of preceding lemma.

Lemma 6 ([9]). For $x, y, z \in X$ and $\alpha \in[0,1]$ we have

$$
d((1-\alpha) x \oplus \alpha y, z) \leq(1-\alpha) d(x, z)+\alpha d(y, z) .
$$

The following lemma is very important to prove our main results, which is an analogue of Proposition 2 of [11] in CAT(0) spaces.

Lemma 7. Let $X$ be a CAT(0) space and let $x \in X$. Suppose $\left\{t_{n}\right\}$ is a sequence in $[b, c]$ for some $b, c \in(0,1)$ and $\left\{x_{n}\right\},\left\{y_{n}\right\}$ are sequences in $X$ such that $\limsup _{n \rightarrow \infty} d\left(x_{n}, x\right) \leq a, \limsup _{n \rightarrow \infty} d\left(y_{n}, x\right) \leq a$, and $\lim _{n \rightarrow \infty} d\left(\left(1-t_{n}\right) x_{n} \oplus t_{n} y_{n}, x\right)=a$ for some $a \geq 0$. Then

$$
\lim _{n \rightarrow \infty} d\left(x_{n}, y_{n}\right)=0 .
$$

Lemma 8. Let $X$ be a Banach space, and let $K$ be a nonempty closed convex subset of $X$. Then,

$$
d(y, T y) \leq\|y-x\|+d(x, T x)+H(T x, T y),
$$

where $x, y \in K$ and $T$ is a multi-valued nonexpansive mapping from $K$ into $C B(K)$.

The following result due to Song and Cho [22] is very useful.

Lemma 9. Let $T: K \rightarrow P(K)$ be a multi-valued mapping and $P_{T}(x)=\{y \in T x$ : $\|x-y\|=d(x, T x)\}$. Then the following are equivalent.

(1) $x \in F(T)$,

(2) $P_{T}(x)=\{x\}$,

(3) $x \in F\left(P_{T}\right)$. Moreover, $F(T)=F\left(P_{T}\right)$.

\section{MAIN RESULTS}

In this section, we opt the following iteration scheme in $\mathrm{CAT}(0)$ spaces.

Let $K$ be a nonempty convex subset of CAT(0) space $X$, let $t: K \rightarrow K$ be a singlevalued nonexpansive mapping and $T: K \rightarrow P B(K)$ be a multi-valued nonexpansive mapping. The sequence $\left\{x_{n}\right\}$ of the modified Ishikawa iteration is defined by

$$
\left\{\begin{array}{l}
y_{n}=\alpha_{n} z_{n} \oplus\left(1-\alpha_{n}\right) x_{n}, \\
x_{n+1}=\beta_{n} t y_{n} \oplus\left(1-\beta_{n}\right) x_{n},
\end{array}\right.
$$


where $x_{0} \in K, z_{n} \in P_{T} x_{n}$ and $0<a \leq \alpha_{n}, \beta_{n} \leq b<1$.

We begin with following lemma.

Lemma 10. Let $K$ be a non-empty bounded closed convex subset of a complete CAT(0) space $X$. Let $t: K \rightarrow K$ be a single-valued nonexpansive mapping and $T: K \rightarrow P B(K)$ be a multi-valued mapping whose $P_{T}$ is a nonexpansive mapping such that $F(t, T) \neq \varnothing$. If $\left\{x_{n}\right\}$ is the sequence of the modified Ishikawa iteration defined by (3.1) with $0<a \leq \alpha_{n}, \beta_{n} \leq b<1$, then $\lim _{n \rightarrow \infty} d\left(x_{n}, w\right)$ exists for all $w \in F(t, T)$.

Proof. Let $w \in F(t, T)$ and $\left\{x_{n}\right\}$ be the sequence described by (3.1). Then in view Lemma 9

$$
w \in P_{T}(w)=\{w\}
$$

Now, consider

$$
\begin{aligned}
d\left(x_{n+1}, w\right) & =d\left(\left(1-\beta_{n}\right) x_{n} \oplus \beta_{n} t y_{n}, w\right) \\
& \leq\left(1-\beta_{n}\right) d\left(x_{n}, w\right) \oplus \beta_{n} d\left(t y_{n}, t w\right) \\
& \leq\left(1-\beta_{n}\right) d\left(x_{n}, w\right) \oplus \beta_{n} d\left(y_{n}, w\right) .
\end{aligned}
$$

But

$$
\begin{aligned}
d\left(y_{n}, w\right) & =d\left(\left(1-\alpha_{n}\right) x_{n} \oplus \alpha_{n} z_{n}, w\right) \\
& \leq\left(1-\alpha_{n}\right) d\left(x_{n}, w\right)+\alpha_{n} d\left(z_{n}, w\right) \\
& =\left(1-\alpha_{n}\right) d\left(x_{n}, w\right)+\alpha_{n} d\left(z_{n}, P_{T} w\right) \\
& \leq\left(1-\alpha_{n}\right) d\left(x_{n}, w\right)+\alpha_{n} H\left(P_{T} x_{n}, P_{T} w\right) \\
& \leq\left(1-\alpha_{n}\right) d\left(x_{n}, w\right)+\alpha_{n} d\left(x_{n}, w\right) \\
& =d\left(x_{n}, w\right) .
\end{aligned}
$$

In view of (3.2) and (3.3), we have

$$
d\left(x_{n+1}, w\right) \leq d\left(x_{n}, w\right) .
$$

Which shows that $\left\{d\left(x_{n}, w\right)\right\}$ is a decreasing sequence of non-negative reals. Thus in all, sequence $\left\{d\left(x_{n}, w\right\}\right.$ is bounded below and decreasing, therefore remains convergent.

Lemma 11. Let $K$ be a non-empty bounded closed convex subset of a complete $C A T(0)$ space $X$. Let $t: K \rightarrow K$ be a single-valued nonexpansive mapping and $T: K \rightarrow P B(K)$ be a multi-valued mapping whose $P_{T}$ is a nonexpansive mapping such that $F(t, T) \neq \varnothing$. If $\left\{x_{n}\right\}$ is the sequence of the modified Ishikawa iteration defined by (3.1) with $0<a \leq \alpha_{n}, \beta_{n} \leq b<1$, then $\lim _{n \rightarrow \infty} d\left(t y_{n}, x_{n}\right)=0$. 
Proof. In view of Lemma 10, $\lim _{n \rightarrow \infty} d\left(x_{n}, w\right)$ exists for all $w \in F(t, T)$. Write

$$
\lim _{n \rightarrow \infty} d\left(x_{n}, w\right)=c \text {. }
$$

Now, consider

$$
\begin{aligned}
d\left(t y_{n}, w\right) & \leq d\left(y_{n}, w\right) \\
& \leq d\left(\left(1-\alpha_{n}\right) x_{n} \oplus \alpha_{n} z_{n}, w\right) \\
& \leq\left(1-\alpha_{n}\right) d\left(x_{n}, w\right)+\alpha_{n} d\left(z_{n}, w\right) \\
& =\left(1-\alpha_{n}\right) d\left(x_{n}, w\right)+\alpha_{n} d\left(z_{n}, P_{T} w\right) \\
& \leq\left(1-\alpha_{n}\right) d\left(x_{n}, w\right)+\alpha_{n} H\left(P_{T} x_{n}, P_{T} w\right) \\
& \leq\left(1-\alpha_{n}\right) d\left(x_{n}, w\right)+\alpha_{n} d\left(x_{n}, w\right) \\
& =d\left(x_{n}, w\right) .
\end{aligned}
$$

On taking limsup of both the sides, we obtain

$$
\limsup _{n \rightarrow \infty} d\left(t y_{n}, w\right) \leq c .
$$

Also,

$$
\begin{aligned}
c & =\lim _{n \rightarrow \infty} d\left(x_{n+1}, w\right) \\
& =\lim _{n \rightarrow \infty} d\left(\left(1-\beta_{n}\right) x_{n} \oplus \beta_{n} t y_{n}, w\right) .
\end{aligned}
$$

In view of (3.5), (3.6), (3.7) and Lemma 7, we get

$$
\lim _{n \rightarrow \infty} d\left(t y_{n}, x_{n}\right)=0 \text {. }
$$

Lemma 12. Let $K$ be a nonempty bounded closed convex subset of a complete CAT(0) space $X$. Let $t: K \rightarrow K$ be a single-valued nonexpansive mapping and $T: K \rightarrow P B(K)$ be a multi-valued mapping whose $P_{T}$ is a nonexpansive mapping such that $F(t, T) \neq \varnothing$. If $\left\{x_{n}\right\}$ is the sequence of the modified Ishikawa iteration defined by (3.1) with $0<a \leq \alpha_{n}, \beta_{n} \leq b<1$, then $\lim _{n \rightarrow \infty} d\left(z_{n}, x_{n}\right)=0$.

Proof. Let $w \in F(t, T)$ and $\left\{x_{n}\right\}$ be the sequence described by (3.1). Since $P_{T}$ is nonexpansive, so in view of Lemma 9, we have

$$
w \in P_{T}(w)=\{w\} .
$$

Now, consider

$$
\begin{aligned}
d\left(x_{n+1}, w\right) & =d\left(\left(1-\beta_{n}\right) x_{n} \oplus \beta_{n} t y_{n}, w\right) \\
& \leq\left(1-\beta_{n}\right) d\left(x_{n}, w\right)+\beta_{n} d\left(t y_{n}, t w\right) \\
& \leq\left(1-\beta_{n}\right) d\left(x_{n}, w\right)+\beta_{n} d\left(y_{n}, w\right) .
\end{aligned}
$$


and therefore

$$
\begin{aligned}
& d\left(x_{n+1}, w\right)-d\left(x_{n}, w\right) \leq \beta_{n}\left(d\left(y_{n}, w\right)-d\left(x_{n}, w\right)\right), \\
& \frac{d\left(x_{n+1}, w\right)-d\left(x_{n}, w\right)}{\beta_{n}} \leq d\left(y_{n}, w\right)-d\left(x_{n}, w\right) .
\end{aligned}
$$

Since $0<a \leq \beta_{n} \leq b<1$, we have

$$
\liminf _{n \rightarrow \infty}\left\{\left(\frac{d\left(x_{n+1}, w\right)-d\left(x_{n}, w\right)}{\beta_{n}}\right)+d\left(x_{n}, w\right)\right\} \leq \liminf _{n \rightarrow \infty} d\left(y_{n}, w\right) .
$$

It follows that

$$
c \leq \liminf _{n \rightarrow \infty} d\left(y_{n}, w\right) .
$$

Since, from (3.3) $\limsup _{n \rightarrow \infty} d\left(y_{n}, w\right) \leq c$, hence we have

$$
\begin{aligned}
c & =\lim _{n \rightarrow \infty} d\left(y_{n}, w\right) \\
& =\lim _{n \rightarrow \infty} d\left(\left(1-\alpha_{n}\right) x_{n} \oplus \alpha_{n} z_{n}, w\right) .
\end{aligned}
$$

Recall that $d\left(z_{n}, w\right)=d\left(z_{n}, P_{T} w\right) \leq H\left(P_{T} x_{n}, P_{T} w\right) \leq d\left(x_{n}, w\right)$. Thus, we have

$$
\limsup _{n \rightarrow \infty} d\left(z_{n}, w\right) \leq \limsup _{n \rightarrow \infty} d\left(x_{n}, w\right)=c .
$$

Owing to (3.9), (3.10) and Lemma 7, we obtain $\lim _{n \rightarrow \infty} d\left(x_{n}, z_{n}\right)=0$.

Lemma 13. Let $K$ be a nonempty bounded closed convex subset of a complete $C A T(0)$ space $X$. Let $t: K \rightarrow K$ be a single-valued nonexpansive mapping and $T: K \rightarrow P B(K)$ be a multi-valued mapping whose $P_{T}$ is a nonexpansive mapping such that $F(t, T) \neq \varnothing$. If $\left\{x_{n}\right\}$ is the sequence of the modified Ishikawa iteration defined by (3.1) with $0<a \leq \alpha_{n}, \beta_{n} \leq b<1$, then $\lim _{n \rightarrow \infty} d\left(t x_{n}, x_{n}\right)=0$.

Proof.

$$
\begin{aligned}
d\left(t x_{n}, x_{n}\right) & \leq d\left(t x_{n}, t y_{n}\right)+d\left(t y_{n}, x_{n}\right) \\
& \leq d\left(x_{n}, y_{n}\right)+d\left(t y_{n}, x_{n}\right) \\
& \leq d\left(x_{n},\left(1-\alpha_{n}\right) x_{n} \oplus \alpha_{n} z_{n}\right)+d\left(t y_{n}, x_{n}\right) \\
& =\alpha_{n} d\left(x_{n}, z_{n}\right)+d\left(t y_{n}, x_{n}\right)
\end{aligned}
$$

therefore,

$$
\lim _{n \rightarrow \infty} d\left(t x_{n}, x_{n}\right) \leq \lim _{n \rightarrow \infty} \alpha_{n} d\left(x_{n}, z_{n}\right)+\lim _{n \rightarrow \infty} d\left(t y_{n}, x_{n}\right) .
$$

Thus by Lemma 11 and Lemma 12, we have

$$
\lim _{n \rightarrow \infty} d\left(t x_{n}, x_{n}\right)=0 .
$$


Now, we prove the following $\Delta$-convergence theorem.

Theorem 1. Let $K$ be a nonempty bounded closed convex subset of a complete CAT(0) space $X$. Let $t: K \rightarrow K$ be a single-valued nonexpansive mapping and $T: K \rightarrow P(K)$ be a multi-valued mapping such that $F(t, T) \neq \varnothing$ with $P_{T}$ is a nonexpansive mapping. Let $\left\{x_{n}\right\}$ be the sequence of the modified Ishikawa iteration defined by (3.1) with $0<a \leq \alpha_{n}, \beta_{n} \leq b<1$, then $\left\{x_{n}\right\} \Delta$-converge to $y \in F(t, T)$.

Proof. From Lemma 10, we have $\lim _{n \rightarrow \infty} d\left(x_{n}, w\right)$ exists for each $w \in F(t, T)$ so that the sequence $\left\{x_{n}\right\}$ is bounded and $\lim _{n \rightarrow \infty} d\left(x_{n}, t x_{n}\right)=0$.

Let $W_{\omega}\left(\left\{x_{n}\right\}\right):=\cup A\left(\left\{u_{n}\right\}\right)$, where union is taken over all subsequences $\left\{u_{n}\right\}$ over $\left\{x_{n}\right\}$. In order to show that the $\Delta$-convergence of $\left\{x_{n}\right\}$ to a common fixed point of $t$ and $T$, firstly we will prove $W_{\omega}\left(\left\{x_{n}\right\}\right) \subset F(t, T)$ and thereafter argue that $W_{\omega}\left(\left\{x_{n}\right\}\right)$ is a singleton set. To show $W_{\omega}\left(\left\{x_{n}\right\}\right) \subset F(t, T)$, let $y \in W_{\omega}\left(\left\{x_{n}\right\}\right)$. Then, there exists a subsequence $\left\{y_{n}\right\}$ of $\left\{x_{n}\right\}$ such that $A\left(\left\{y_{n}\right\}\right)=y$. By Lemmas 1 and 2 , there exists a subsequence $\left\{w_{n}\right\}$ of $\left\{y_{n}\right\}$ such that $\Delta-\lim _{n} w_{n}=w$ and $w \in$ $K$. Since, $\lim _{n \rightarrow \infty} d\left(t w_{n}, w_{n}\right)=0$ so that in view of Lemma $4, w \in F(t)$. Also, $\lim _{n \rightarrow \infty} d\left(x_{n}, P_{T} x_{n}\right) \leq d\left(x_{n}, z_{n}\right)$. In view of Lemma 12, we have $\lim _{n \rightarrow \infty} d\left(x_{n}, P_{T} x_{n}\right)=$ 0 and so is $\lim _{n \rightarrow \infty} d\left(w_{n}, P_{T} w_{n}\right)=0$. Owing to Lemma $4, w \in F\left(P_{T}\right)$ and hence $w \in F(t, T)$. Now, we claim that $w=y$. Let on contrary that $w \neq y$, then we have

$$
\begin{aligned}
\limsup _{n \rightarrow \infty} d\left(w_{n}, w\right) & <\limsup _{n \rightarrow \infty} d\left(w_{n}, y\right) \\
\leq & \limsup _{n \rightarrow \infty} d\left(y_{n}, y\right) \\
& <\limsup _{n \rightarrow \infty} d\left(y_{n}, w\right) \\
& =\limsup _{n \rightarrow \infty} d\left(x_{n}, w\right) \\
& =\limsup _{n \rightarrow \infty} d\left(w_{n}, w\right)
\end{aligned}
$$

which is a contradiction and hence $w=y \in F$. To show that $W_{\omega}\left(\left\{\left(x_{n}\right\}\right)\right.$ is a singleton, let $\left\{y_{n}\right\}$ be a subsequence of $\left\{x_{n}\right\}$. In view of Lemmas 1 and 2, there exists a subsequence $\left\{w_{n}\right\}$ of $\left\{y_{n}\right\}$ such that $\Delta-\lim _{n} w_{n}=w$. Let $A\left(\left\{y_{n}\right\}\right)=y$ and $A\left(\left\{x_{n}\right\}\right)=x$. Earlier, we have shown that $y=w$, therefore it is enough to show $w=x$. If $w \neq x$, so by Lemma $10\left\{d\left(x_{n}, w\right)\right\}$ is convergent. By uniqueness of asymptotic center

$$
\begin{aligned}
\limsup _{n \rightarrow \infty} d\left(w_{n}, w\right) & <\limsup _{n \rightarrow \infty} d\left(w_{n}, x\right) \\
& \leq \limsup _{n \rightarrow \infty} d\left(x_{n}, x\right) \\
& <\limsup _{n \rightarrow \infty} d\left(x_{n}, w\right) \\
& =\limsup _{n \rightarrow \infty} d\left(w_{n}, w\right)
\end{aligned}
$$


which is a contradiction so that the conclusion follows.

Theorem 2. Let $K$ be a nonempty bounded closed convex subset of a complete CAT(0) space $X$. Let $t: K \rightarrow K$ be a single-valued nonexpansive mapping and $T: K \rightarrow P(K)$ be a multi-valued mapping whose $P_{T}$ is a nonexpansive mapping such that $F(t, T) \neq \varnothing$. Let $\left\{x_{n}\right\}$ be the sequence of the modified Ishikawa iteration defined by (3.1) with $0<a \leq \alpha_{n}, \beta_{n} \leq b<1$, then $\left\{x_{n_{i}}\right\} \rightarrow y$ for some subsequence $\left\{x_{n_{i}}\right\}$ of $\left\{x_{n}\right\}$ implies $y \in F(t, T)$.

Proof. Assume that $\lim _{i \rightarrow \infty} d\left(x_{n_{i}}, y\right)=0$. By Lemma 13, we obtain

$$
\lim _{i \rightarrow \infty} d\left(t x_{n_{i}}, x_{n_{i}}\right)=0
$$

Now, we have

$$
\begin{aligned}
d\left(x_{n_{i}}, t y\right) & \leq d\left(x_{n_{i}}, t x_{n_{i}}\right)+d\left(t x_{n_{i}}, t y\right) \\
& \leq d\left(x_{n_{i}}, t x_{n_{i}}\right)+d\left(x_{n_{i}}, y\right) .
\end{aligned}
$$

On taking limit of both the sides, we get

$$
\lim _{i \rightarrow \infty} d\left(x_{n_{i}}, t y\right)=0 .
$$

Hence by the uniqueness of limit, we obtain $y=t y$, that is, $y \in F(t)$. By Lemma 8 , we have

$$
\begin{array}{r}
d\left(y, P_{T} y\right) \leq d\left(y, x_{n_{i}}\right)+d\left(x_{n_{i}}, P_{T} x_{n_{i}}\right)+H\left(P_{T} x_{n_{i}}, P_{T} y\right) \\
\leq d\left(y, x_{n_{i}}\right)+d\left(x_{n_{i}}, z_{n_{i}}\right)+d\left(x_{n_{i}}, y\right) \rightarrow 0
\end{array}
$$

as $i \rightarrow \infty$. It follows that $y \in F\left(P_{T}\right)=F(T)$. Thus $y \in F(t, T)$.

Theorem 3. Let $K$ be a nonempty compact convex subset of a complete $C A T(0)$ space $X$. Let $t: K \rightarrow K$ be a single-valued nonexpansive mapping and $T: K \rightarrow$ $P B(K)$ be a multi-valued mapping whose $P_{T}$ is a nonexpansive mapping such that $F(t, T) \neq \varnothing$. Let $\left\{x_{n}\right\}$ be the sequence of the modified Ishikawa iteration defined by (3.1) with $0<a \leq \alpha_{n}, \beta_{n} \leq b<1$, then $\left\{x_{n}\right\}$ converges strongly to a common fixed point of $t$ and $T$.

Proof. Since $\left\{x_{n}\right\}$ is contained in $K$ which is compact, there exists a subsequence $\left\{x_{n_{i}}\right\}$ of $\left\{x_{n}\right\}$ such that $\left\{x_{n_{i}}\right\}$ converges strongly to some point $y \in K$, that is, $\lim _{i \rightarrow \infty} d\left(x_{n_{i}}, y\right)=0$. By Theorem 2, we get $y \in F(t, T)$ and by Lemma 10, we have that $\lim _{n \rightarrow \infty} d\left(x_{n}, y\right)$ exists. It must be the case in which $\lim _{n \rightarrow \infty} d\left(x_{n}, y\right)=\lim _{i \rightarrow \infty} d\left(x_{n_{i}}, y\right)=$ 0 . Thus, $\left\{x_{n}\right\}$ converges strongly to $y \in F(t, T)$.

Khan and Fukhar-ud-din [12] introduced the so-called condition $\left(A^{\prime}\right)$ for two mappings and gave an improved version in [10] of condition (I) of Senter and Dotson [18]. A hybrid version of condition $\left(A^{\prime}\right)$ for a pair of single valued and multivalued mapping which is weaker than compactness of the domain, is given as follows: 
A pair of single-valued mapping $t: K \rightarrow K$ and a multi-valued mapping $T: K \rightarrow$ $C B(K)$ is said to satisfy condition $\left(A^{\prime}\right)$ if there exists a nondecreasing function $f$ : $[0, \infty) \rightarrow[0, \infty)$ with $f(0)=0, f(r)>0$ for all $r \in(0, \infty)$ such that either $d(x, t x) \geq$ $f(d(x, F))$ or $d(x, T x) \geq f(d(x, F))$ for all $x \in K$.

Theorem 4. Let $K$ be a nonempty bounded closed convex subset of a complete $C A T(0)$ space $X$. Let $t: K \rightarrow K$ be a single-valued nonexpansive mapping and $T$ : $K \rightarrow P B(K)$ be a multi-valued mapping whose $P_{T}$ is a nonexpansive mapping such that $F(t, T) \neq \varnothing$. Moreover pair $\left(t, P_{T}\right)$ satisfies condition $\left(A^{\prime}\right)$. If $\left\{x_{n}\right\}$ is sequence of the modified Ishikawa iteration defined by (3.1) with $0<a \leq \alpha_{n}, \beta_{n} \leq b<1$, then $\left\{x_{n}\right\}$ converges strongly to a common fixed point of $t$ and $T$.

Proof. First, we show that $F(t, T)$ is closed. Let $\left\{x_{n}\right\}$ be a sequence in $F(t, T)$ converging to some point $z \in K$. Since

$$
\begin{aligned}
d\left(x_{n}, t z\right) & =d\left(t x_{n}, t z\right) \\
& \leq d\left(x_{n}, z\right),
\end{aligned}
$$

we have

$$
\limsup _{n} d\left(x_{n}, t z\right) \leq \limsup d\left(x_{n}, z\right)=0 .
$$

By uniqueness of the limit, we have $t z=z$. Also,

$$
\begin{gathered}
d\left(x_{n}, P_{T} z\right) \leq H\left(P_{T} x_{n}, P_{T} z\right) \\
\leq d\left(x_{n}, z\right) \rightarrow 0 \text { as } n \rightarrow \infty .
\end{gathered}
$$

This implies that $\left\{x_{n}\right\}$ converges to some point of $P_{T} z$ and hence $z \in F\left(P_{T}\right)=$ $F(T)$.

By Lemma 10, $\lim _{n \rightarrow \infty} d\left(x_{n}, p\right)$ exists for all $p \in F(t, T)$ and let us take to be $c$. If $c=$ 0 , then there is nothing to prove. If $c>0$, then in view of Equation (3.4) for all $p \in$ $F(t, T)$, we have

$$
d\left(x_{n+1}, p\right) \leq d\left(x_{n}, p\right),
$$

so that

$$
\inf _{p \in F(t, T)} d\left(x_{n+1}, p\right) \leq \inf _{p \in F(t, T)} d\left(x_{n}, p\right),
$$

which amounts to say that

$$
d\left(x_{n+1}, F(t, T)\right) \leq d\left(x_{n}, F(t, T)\right)
$$

and hence $\lim _{n \rightarrow \infty} d\left(x_{n}, F(t, T)\right)$ exists. Owing to condition $\left(A^{\prime}\right)$ there exists a nondecreasing function $f$ such that

$$
\lim _{n \rightarrow \infty} f\left(d\left(x_{n}, F(t, T)\right)\right) \leq \lim _{n \rightarrow \infty} d\left(x_{n}, t x_{n}\right)=0
$$

or,

$$
\lim _{n \rightarrow \infty} f\left(d\left(x_{n}, F(t, T)\right)\right) \leq \lim _{n \rightarrow \infty} d\left(x_{n}, P_{T} x_{n}\right) \leq \lim _{n \rightarrow \infty} d\left(x_{n}, z_{n}\right)=0
$$


so that in both the cases $\lim _{n \rightarrow \infty} f\left(d\left(x_{n}, F(t, T)\right)\right)=0$. Since, $f$ is a nondecreasing function and $f(0)=0$, therefore $\lim _{n \rightarrow \infty} d\left(x_{n}, F(t, T)\right)=0$.

This implies that there exists a subsequence $\left\{x_{n_{k}}\right\}$ of $\left\{x_{n}\right\}$ such that

$$
d\left(x_{n_{k}}, p_{k}\right) \leq \frac{1}{2^{k}} \text { for all } \mathrm{k} \geq 1
$$

where $\left\{p_{k}\right\}$ is in $F(t, T)$. By Lemma 10 , we have

$$
d\left(x_{n_{k+1}}, p_{k}\right) \leq d\left(x_{n_{k}}, p_{k}\right) \leq \frac{1}{2^{k}},
$$

so that

$$
\begin{aligned}
d\left(p_{k+1}, p_{k}\right) & \leq d\left(p_{k+1}, x_{n_{k+1}}\right)+d\left(x_{n_{k+1}}, p_{k}\right) \\
& \leq \frac{1}{2^{k+1}}+\frac{1}{2^{k}}<\frac{1}{2^{k-1}},
\end{aligned}
$$

which implies that $\left\{p_{k}\right\}$ is a Cauchy sequence. Since $F(t, T)$ is closed, therefore $\left\{p_{k}\right\}$ is a convergent sequence. Write $\lim _{k \rightarrow \infty} p_{k}=p$. Now, in order to show that $\left\{x_{n}\right\}$ converges to $p$, lets proceed as follows:

$$
d\left(x_{n_{k}}, p\right) \leq d\left(x_{n_{k}}, p_{k}\right)+d\left(p_{k}, p\right) \rightarrow 0 \text { as } k \rightarrow \infty,
$$

so that $\lim _{k \rightarrow \infty} d\left(x_{n_{k}}, p\right)=0$. Since $\lim _{n \rightarrow \infty} d\left(x_{n}, p\right)$ exists, therefore $x_{n} \rightarrow p$.

Remark 1. The condition of nonexpansiveness on $P_{T}$ is necessary. By the following example we can illustrate that $P_{T}$ need not be necessarily nonexpansive even $T$ is nonexpansive.

Example 1. Let $X$ be a rectangle with vertices $(0,0),(2,0),(2,1)$ and $(0,1)$. Define $T((u, v))=T((u, 0))=\left[\left(\frac{u}{\sqrt{2}}, \frac{u}{\sqrt{2}}\right),\left(1+\frac{u}{\sqrt{2}}, \frac{u}{\sqrt{2}}\right)\right]$ for $u \leq \sqrt{2}$ and $T(u, v)=T(u, 0)=$ $[(1,1),(2,1)]$ for $u>\sqrt{2}$. Then it can be verified that

$$
H\left(T u_{1}, T u_{2}\right)=\left|u_{1}-u_{2}\right|
$$

for $u_{1}, u_{2} \leq \sqrt{2}$ and less than other case so that $T$ is nonexpansive. Also, if $x=(0,1)$ then $P_{T}(x)=(0,0)$ while for $p=(\sqrt{2}, 1), P_{T}(p)=(\sqrt{2}, 1)$. Now, $\| P_{T}(p)-$ $P_{T}(x) \|=\sqrt{3}$ while $\|x-p\|=\sqrt{2}$ that is $\left\|P_{T}(p)-P_{T}(x)\right\|>\|x-p\|$ which assures that $P_{T}$ is not a nonexpansive mapping.

\section{ACKNOWLEDGMENTS}

Authors are thankful to the learned referee for suggestions. The first author is grateful to University Grants Commission, India for providing financial assistance in the form of the BSR Start-Up Research Grant. The third author is supported by the Ministry of Education, Science and Technological Development of the Republic of Serbia, Grant No. 174025. 


\section{REFERENCES}

[1] N. Akkasriworn, K. Sokhuma, and K. Chuikamwong, "Ishikawa iterative process for a pair of Suzuki generalized nonexpansive single valued and multivalued mappings in Banach spaces." Int. J. Math. Anal., vol. 19, pp. 923-932, 2012.

[2] V. Berinde, Iterative Approximation of Fixed Points, in: Lecture Notes in Mathematics. Berlin: Springer, 2007.

[3] M. Bridson and A. Haeflinger, Metric spaces of nonpositive curvature. Berlin: Springer-Verlag, 1999.

[4] S. Dhompongsa, A. Kaewkhao, and B. Panyanak, "Lim's theorems for multivalued mappings in CAT(0) spaces.” J. Math. Anal. Appl., vol. 312, pp. 478-487, 2005.

[5] S. Dhompongsa, A. Kaewkhao, and B. Panyanak, "Browder's convergence theorem for multivalued mappings without endpoint condition.” Topology Appl., vol. 159, pp. 2757-2763, 2012.

[6] S. Dhompongsa, A. Kaewkhao, and B. Panyanak, "On Kirk's strong convergence theorem for multivalued nonexpansive mappings on CAT(0) spaces." Nonlinear Anal., vol. 75, pp. 459-468, 2012.

[7] S. Dhompongsa, W. A. Kirk, and B. Sims, "Fixed points of uniformly lipschitzian mappings." Nonlinear Anal., vol. 65, pp. 762-772, 2006.

[8] S. Dhompongsa, W. A. Kirk, and B. Panyanak, "Nonexpansive set-valued mappings in metric and Banach spaces.” J. Nonlinear Convex Anal., vol. 8, pp. 35-45, 2007.

[9] S. Dhompongsa and B. Panyanak, "On $\Delta$-convergence theorems in CAT(0) space." Comput. Math. Appl., vol. 56, pp. 2572-2579, 2008.

[10] H. Fukhar-ud-din and S. H. Khan, "Convergence of iterates with errors of asymptotically quasinonexpansive mappings and applications." J. Math. Anal. Appl., vol. 328, pp. 821-829, 2007.

[11] K. Goebel and W. A. Kirk, "Iteration processes for nonexpansive mappings, Topological Methods in Nonlinear Functional Analysis.” Amer. Math. Soc., vol. 21, pp. 115-123, 1983.

[12] S. H. Khan and H. Fukhar-ud-din, "Weak and strong convergence of a scheme with errors for two nonexpansive mappings." Nonlinear Anal., vol. 8, pp. 1295-1301, 2005.

[13] W. A. Kirk, "Geodesic geometry and fixed point theory." Colec. Abierta, Univ. Sevilla Secr. Publ., Seville, vol. 64, pp. 195-225, 2003.

[14] W. A. Kirk and B. Panyanak, "A concept of convergence in geodesic spaces." Nonlinear Anal., vol. 68, pp. 3689-3696, 2008.

[15] T. C. Lims, "Remarks on some fixed point theorems." Proc. Amer. Math. Soc., vol. 60, pp. 179_ 182, 1976.

[16] B. Panyanak, "Mann and Ishikawa iterative processes for multivalued mappings in Banach spaces.” Comput. Math. Appl., vol. 54, pp. 872-877, 2007.

[17] K. P. R. Sastry and G. V. R. Babu, "Convergence of Ishikawa iterates for a multi-valued mapping with a fixed point." Czechoslovak Math. J., vol. 55, pp. 817-826, 2005.

[18] H. F. Senter and D. G. dotson, "Approximating fixed points of nonexpansive mappings." Proc. Amer. Math. Soc., vol. 44, pp. 375-380, 1974.

[19] K. Sokhuma, " $\Delta$-Convergence theorems for a pair of single-valued and multivalued nonexpansive mappings in CAT(0) spaces.” J. Math. Anal., vol. 4, pp. 23-31, 2013.

[20] K. Sokhuma, "Convergence theorems for a pair of asymptotically and multi-valued nonexpansive mapping in Banach spaces.” Int. J. Math. Anal., vol. 7, pp. 927-936, 2013.

[21] K. Sokhuma and A. Kaewkhao, "Ishikawa iterative process for a pair of single-valued and multivalued nonexpansive mappings in Banach spaces." Fixed Point Theory Appl., vol. 2010, 2010.

[22] Y. Song and Y. J. Cho, "Some notes on Ishikawa iteration for multi-valued mappings." Bull. Korean Math. Soc., vol. 48, pp. 575-584, 2011. 
[23] Y. Song and H. Wang, "Convergence of iterative algorithms for multivalued mappings in Banach spaces.” Nonlinear Anal., vol. 70, pp. 1547-1556, 2009.

[24] I. Uddin and M. Imdad, "A new iteration scheme for a hybrid pair of nonexpansive mappings." Honam Math. J., vol. 38, pp. 127-139, 2016.

[25] I. Uddin, M. Imdad, and J. Ali, "Convergence theorems for a hybrid pair of generalized nonexpansive mappings in Banach spaces.” Bull. Malays. Math. Sci. Soc., vol. 38, pp. 695-705, 2015.

Authors' addresses

\section{Izhar Uddin}

Department of Mathematics, Jamia Millia Islamia, New Delhi, India

E-mail address: izharuddin1@jmi.ac.in

Javid Ali

Department of Mathematics, Aligarh Muslim University, 202002 Aligarh, India

E-mail address: javid.mmeamu.ac.in

Vladimir Rakočević

University of Niš, Faculty of Sciences and Mathematics, Višegradska 33, 18000 Nišs, Serbia

E-mail address: vrakocesbb.rs 